\title{
A New Modified Peck Formula for Predicting the Surface Settlement Based on Stochastic Medium Theory
}

\author{
Zhanping Song $\mathbb{D}^{1,2}$ Xiaoxu Tian $\mathbb{D}^{1,2}$ and Yuwei Zhang $\mathbb{D}^{1,2}$ \\ ${ }^{1}$ School of Civil Engineering, Xi'an University of Architecture and Technology, Xi'an, Shaanxi 710055, China \\ ${ }^{2}$ Shaanxi Key Laboratory of Geotechnical and Underground Space Engineering, Xi'an University of Architecture and Technology, \\ Xi'an, Shaanxi 710055, China \\ Correspondence should be addressed to Xiaoxu Tian; tianxiaoxu@xauat.edu.cn and Yuwei Zhang; 1032659676@qq.com
}

Received 5 July 2019; Accepted 6 August 2019; Published 22 October 2019

Academic Editor: Castorina S. Vieira

Copyright (c) 2019 Zhanping Song et al. This is an open access article distributed under the Creative Commons Attribution License, which permits unrestricted use, distribution, and reproduction in any medium, provided the original work is properly cited.

\begin{abstract}
Peck method and stochastic medium method are the two most commonly used methods to estimate surface settlement caused by tunnel excavation. However, the Peck method was not suitable for a shallow-buried tunnel, and the calculation process of the stochastic medium theory was complicated. To solve this problem, in this paper, a simple and accurate prediction approach for surface settlement was obtained by improving the Peck method based on the basic idea of stochastic medium theory. In detail, the over-excavation area of the tunnel was divided into $n$ independent units, and the surface settlement caused by the collapse of each unit was calculated, respectively. Then, the total surface settlement can be obtained by superimposing surface settlement induced by each unit. Taking the shallow-buried section of Mulingguan tunnel entrance as a case, the surface settlement calculated by the modified Peck formula and original Peck formula was compared with the observed data, respectively. The comparison results indicated that the surface settlement calculated by the modified Peck formula is closer to the observed data than that calculated by the original Peck formula in the calculation process of surface settlement of shallow-buried tunnel. The table of recommendation for the number of units can be obtained by a discussion of reasonable $n$ values. Finally, the difference between the original Peck formula and the modified Peck formula was analysed, and the results showed that the change rule of the surface settlement is consistent under the tunnel depth, internal friction angle, and ground loss of the tunnel. However, the calculation error of the surface settlements calculated by the original Peck formula is more significant than that calculated by modified Peck formula under the tunnel diameter ratio being less than 1.75. The modified Peck formula is more suitable for calculating the surface settlement under internal angle friction being less than $20^{\circ}$ or greater than $40^{\circ}$. The research results expand the scope of application of the original Peck formula and enrich the calculation approach of surface settlement induced by underground excavation in tunnel construction.
\end{abstract}

\section{Introduction}

Subway tunnels and other public facility tunnels are often constructed by the subsurface excavation method due to the problem of traffic congestion and the environmental quality requirements. The underground excavation of urban subway tunnels is bound to cause surface settlement and even cause surface collapse, thus affecting the safety of driving and pedestrians [1-8]. Therefore, it is of great practical significance to predict surface settlement induced by the underground excavation of urban subway tunnels to prevent excessive surface settlement or surface collapse.

At present, there are many methods for predicting surface settlement induced by tunnel construction, for example, the empirical formula method [9-12], elastic strain method [13-16], the airy stress function method [17-21], stochastic medium theory [22-24], numerical simulation method [25, 26], and centrifuge test method [27, 28]. According to the above literature review, although there are many methods to predict surface settlement, the Peck method and stochastic medium theory are still the two most 
widely applied approaches to predict surface settlement. Therefore, many scholars modified and extended the Peck formula and stochastic medium theory. For example, according to the research of Jacobsz et al. [29] and Vorster et al. [30], the width of the settlement trough is related to the nature of soil. It indicated that measured data conform to the normal distribution law and its correlation coefficient was above 0.8 by using the Peck formula to fit the results of up to 51 settlement curves in different parts of the world [31]. Han et al. evaluated the applicability of the Peck formula in different regions by discussed and analysed surface settlement observed data collected from more than 30 groups of subway construction in China; the results showed that the Peck method was not suitable for shallow-buried tunnels [32].

Another method to predict surface settlement and deformation induced by tunnel construction is the stochastic medium theory. The stochastic medium theory was proposed by the Polish scholar Litwiniszyn to study the influence of coal seam mining on surface displacement. The rock and soil are regarded as a stochastic medium, and surface displacement caused by soil excavation is considered to be a stochastic process. Subsequently, the stochastic medium theory was introduced by Chinese scholars into the study of predicting surface settlement caused by urban subway construction $[33,34]$. Compared with the Peck method, stochastic medium theory can be applied to a shallow-buried tunnel and various excavation sections, which has more advantages [35, 36]. However, its calculation method is complicated, so it is difficult to be widely used in engineering.

With respect to the problems as mentioned earlier, a simple and accurate prediction method for surface settlement was presented by improving the Peck formula based on the basic idea of stochastic medium theory in this paper. The shallow-buried section of the Mulingguan tunnel entrance is taken as an actual case to verify the rationality of the modified Peck formula. Furthermore, the calculation precision of the various number of units is analysed to obtain a reasonable number of division units. Finally, the difference between the modified Peck formula and original Peck formula is discussed, which further verified the rationality of the modified Peck formula.

\section{Stochastic Medium Theory and Peck Formula}

2.1. Stochastic Medium Theory. Litwiniszyn proposed the stochastic medium theory in 1957. He considered that surface settlement caused by the complete excavation of a subsurface unit is a stochastic event. In the plane, the excavated unit $d \xi d \eta$ at the subsurface depth of $H$ completely collapses, and the settlement is [22]

$$
W_{e(x)}=\frac{1}{r_{(\eta)}} \exp \left[-\frac{\pi}{r_{(\eta)}^{2}}(x-\xi)^{2}\right] d \xi d \eta,
$$

where $\xi$ and $\eta$ are the horizontal and vertical coordinates of the collapsed unit in the plane, respectively; $r_{(\eta)}$ is the influence radius; and $r_{(\eta)}=\eta / \tan \beta, \beta$ is the influence angle of overlying rock and soil layer.

In tunnel engineering, the actual volume of the excavated soil is usually more massive than the design limit of the tunnel due to the limitation of construction technology and geological conditions. This part of the overexcavation continues to sink with the progress of construction until the lining of the tunnel is closed and formed. In the stochastic medium theory, the soil mass of the over-excavation part of the tunnel can be regarded as complete collapse, as shown in Figure 1. If to integrate part over-excavation, then we can get the surface settlement expressions:

$$
S_{(x)}=\iint_{\Omega} \frac{1}{r_{(\eta)}} \exp \left[-\frac{\pi}{r_{(\eta)}^{2}}(x-\xi)^{2}\right] d \xi d \eta
$$

It was difficult for the engineers to calculate the surface settlement due to the above integrand being nonintegrable.

2.2. Peck Formula. In 1969, Peck proposed that the ground settlement conforms to the law of normal distribution by summarising the measured data of ground settlement caused by a large number of tunnel construction at that time [9]. The following formula can be used to calculate surface settlement:

$$
S_{(x)}=S_{\max } \exp \left(-\frac{x^{2}}{2 i^{2}}\right),
$$

where $S_{(x)}$ is the surface settlement value at a distance of $x$ from the central axis of the tunnel; $S_{\max }$ is the maximum value of surface settlement, generally located in the axis of the tunnel; and $i$ is the width of the surface settlement trough and is the horizontal distance from the axis of the tunnel to the inflexion point of the settlement curve (as shown in Figure 1). The Peck method was not suitable for the shallowburied tunnel according to the analysis of the applicability of the Peck formula in different regions [32].

\section{Modified Peck Formula Based on Stochastic Medium Theory}

3.1. Correlation between Stochastic Medium Theory and Peck Formula. Assume that the surface settlement calculated by the Peck method for the same project is equal to that calculated by stochastic medium theory. According to the concept of ground loss in the Peck method, the lost volume of soil $\left(V_{l}\right)$ is equal to the volume enclosed by the surface settlement curve and the original surface level:

$$
\begin{aligned}
V_{l} & =\int_{-\infty}^{+\infty} S_{\max } \exp \left(-\frac{x^{2}}{2 i^{2}}\right) d x \\
& =S_{\max } \cdot \sqrt{2 \pi} i .
\end{aligned}
$$

The mathematical meaning of $V_{l}$ is the area enclosed by the normal distribution curve $S_{(x)}$ and the horizontal coordinate axis. According to equation (5), this area is equal to the triangle area with height $S_{\max }$ and base $2 \sqrt{2 \pi} i$ (as shown 


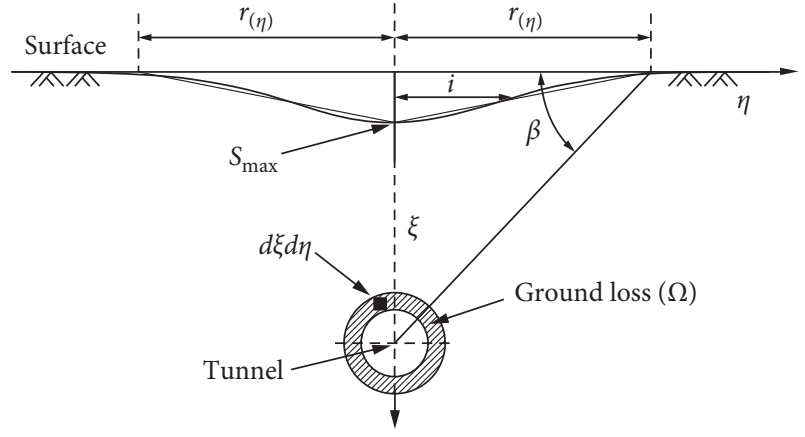

FIGURE 1: Surface settlement curve.

in Figure 1). Therefore, the following correlation can be established between $r_{(\eta)}$ and $i$ :

$$
r_{(\eta)}=\sqrt{2 \pi} i .
$$

Equation (3) can be rewritten as

$$
S_{(x)}=\frac{V_{l}}{r_{(\eta)}} \exp \left(-\frac{\pi \cdot x^{2}}{r_{(\eta)}^{2}}\right) .
$$

It can be seen that the Peck formula regards the overall over-excavation part $\left(V_{l}\right)$ of the tunnel as a unit by comparing equations (6) and (1). The surface settlement caused by excavation conforms to the normal distribution law. Therefore, it can be considered that the Peck formula is an approximate calculation of stochastic medium theory, and the difference lies in that stochastic medium theory regards the over-excavation area as countless tiny units, while the Peck formula regards the whole over-excavation part as a tiny unit. It is assumed that the over-excavation area of the tunnel can be considered as a tiny unit in comparison with the tunnel depth and the area affected by the surface settlement caused by construction. Then the Peck formula is an approximate method of calculating the surface settlement of stochastic medium theory under the condition of large depth. The calculation accuracy of the Peck formula will increase with the increase of the tunnel depth of the tunnel and the influence area of surface settlement. With the decrease of the tunnel depth and the affected area, the accuracy of the surface settlement value calculated by the Peck formula becomes worse.

3.2. Modified Peck Formula. It was found that the Peck formula refers to treating the over-excavation part of the tunnel as a tiny unit by comparing equations (6) and (1), and the surface settlement caused by its complete collapse conforms to the normal distribution law, so there is an error in calculating the surface settlement. Equation (2) is the theoretical solution of surface settlement based on the stochastic medium theory. However, the solution is extremely complex and difficult to be widely applied in the engineering field due to the nonintegrability of its original function.

It is assumed that the over-excavation part of the tunnel is centred on the centre of the tunnel circle and evenly

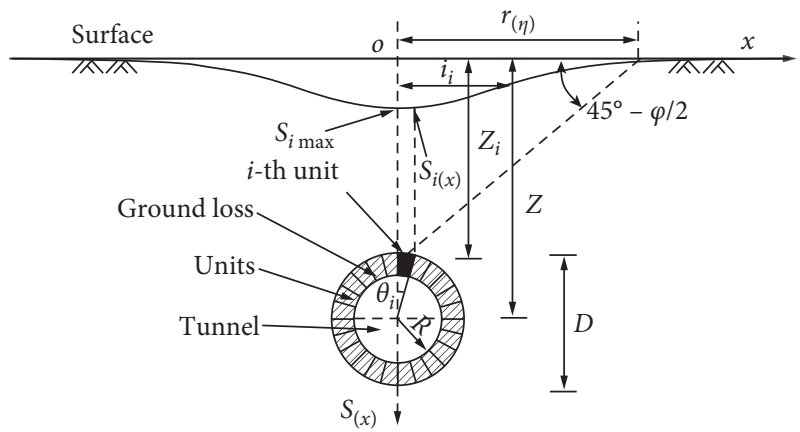

Figure 2: Schematic diagram of over-excavation unit division.

distributed on the ring around the outer diameter of the tunnel [34], as shown in Figure 2. The over-excavation part of the tunnel is divided into $n$ tiny units with equal area. It is assumed that the collapse between tiny units is independent of each other, and surface settlement caused by the collapse of each tiny unit is calculated, respectively. Based on the principle of displacement superposition, the total settlement induced by tunnel excavation is equal to the sum of surface settlement caused by $n$ independent units. This method for calculating surface settlement induced is called the modified Peck method in this paper. The more the number of the unit, the more accurate the surface settlement obtained by this method will be.

According to equations (1) and (3), the surface settlement induced by the $i$-th unit can be expressed as

$$
S_{i(x)}=S_{i \max } \cdot \exp \left[-\frac{\left(x-R \cdot \sin \theta_{i}\right)^{2}}{2 i_{i}^{2}}\right],
$$

where $R$ is the outer diameter of the tunnel, $\theta_{i}$ is the angle between $i$ unit and the vertical axis of the tunnel, and $i_{i}$ is the width of the settlement trough caused by $i$ units.

The width of the settlement trough caused by tunnel construction can be expressed as

$$
i_{i}=\frac{z_{i}}{\sqrt{2 \pi} \cdot \tan ((45-\varphi) / 2)},
$$

where $z_{i}$ is the depth of the unit and $\varphi$ is the internal friction angle of the soil.

The expression of the total surface settlement curve is

$$
S_{(x)}=\sum_{i=1}^{n} S_{i \max } \cdot \exp \left[-\frac{\left(x-R \cdot \sin \theta_{i}\right)^{2}}{2 i_{i}^{2}}\right] .
$$

In the actual calculation, the number $n$ of over-excavation sections of the tunnel can be determined according to the tunnel depth and section size of the tunnel. The larger the $n$ is, the more accurate the calculation result will be.

\section{A Case Study}

In this section, the engineering object of the shallow-buried section at the entrance of the Mulingguan tunnel [37] was used to analyse the variation law of the surface settlement curve under different $n$ values to verify the modified Peck formula. 


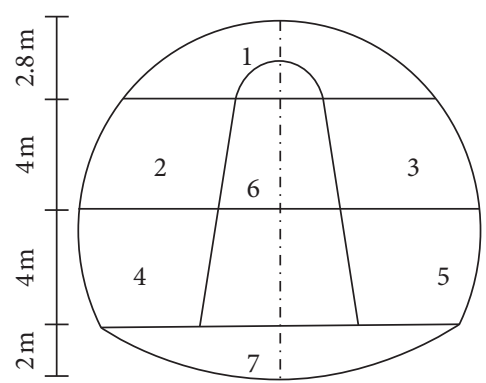

(a)

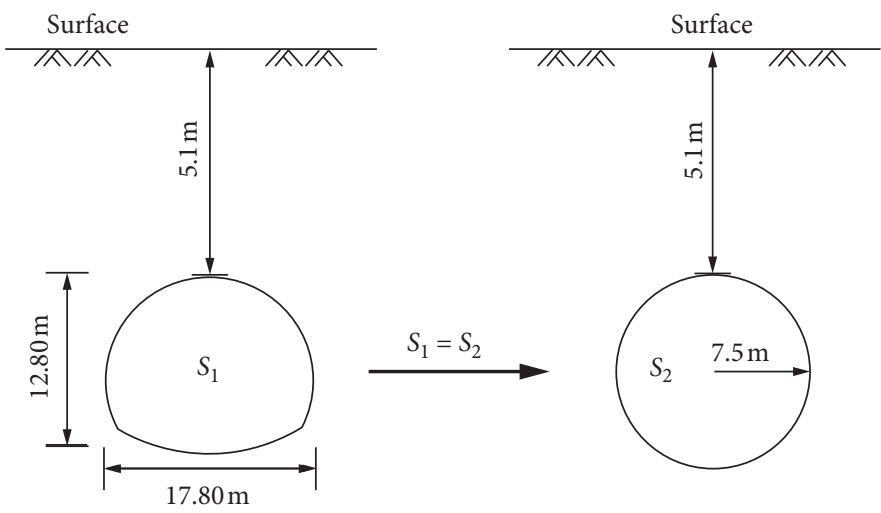

(b)

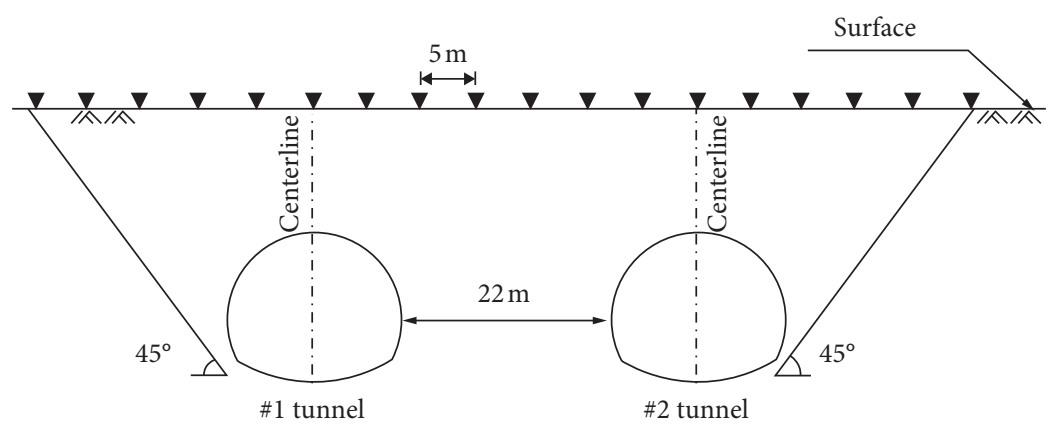

(c)

FIgUre 3: (a) Tunnel excavation steps. (b) Tunnel depth and section size. (c) Arrangement of surface settlement observing points.

The depth of at the entrance of the Mulingguan tunnel is $5.1 \mathrm{~m}$, the grade of surrounding rock is $\mathrm{V}$ grade, the ground loss rate is $0.45 \%$ [38], and the friction angle of soil is $30^{\circ}$ (Code for Design of Railway Tunnel, China [39]). For the convenience of calculation, the original tunnel section is equivalent to a circular section according to the principle of equal area and buried depth. After \#1 tunnel has been excavated for $50 \mathrm{~m}, \# 2$ tunnel was excavated, and the three-step and seven-step method was adopted for construction. For the convenience of calculation, the equivalent radius of the tunnel section is taken to be $7.5 \mathrm{~m}$, as shown in Figures 3(a) and 3(b). A total of 18 observing points are arranged above the tunnel at an interval of $5 \mathrm{~m}$ to study the deformation law of surface settlement, as shown in Figure 3(c). The final surface settlement curve of \#1 tunnel after the excavation is shown in Figure 4(a). The maximum surface settlement value is $32.8 \mathrm{~mm}$, and the actual width of the settlement trough obtained by fitting observing data is $9.0 \mathrm{~m}$. The final surface settlement curve of \#2 tunnel after the excavation is shown in Figure 4(b). The maximum surface settlement value of \#1 tunnel is $34.2 \mathrm{~mm}$, and the maximum surface settlement value of \#2 tunnel is $37.9 \mathrm{~mm}$.

According to equation (9), the settlement curve expressions of the tunnel surface at the time when the division number of the over-excavation part is $24,20,16,12,8$, and 4 are calculated, respectively. The calculation results are shown in Table 1 and Figure 4.

According to Table 1, when the number of units increases from 4 to 8 , the relative error of the width of the settlement trough decreased from $18.22 \%$ to $3.0 \%$. If the number $n$ continues to increase, the variation of relative error is less than $1 \%$. When the number of partition units is greater than 16 , the relative error is unchanged with the increase of $n$.

The shape of the surface settlement curve can be seen according to the number of different units given in Figure 4(a). When the number of units is $n=4$, the settlement curve calculated by using equation (9) and the 


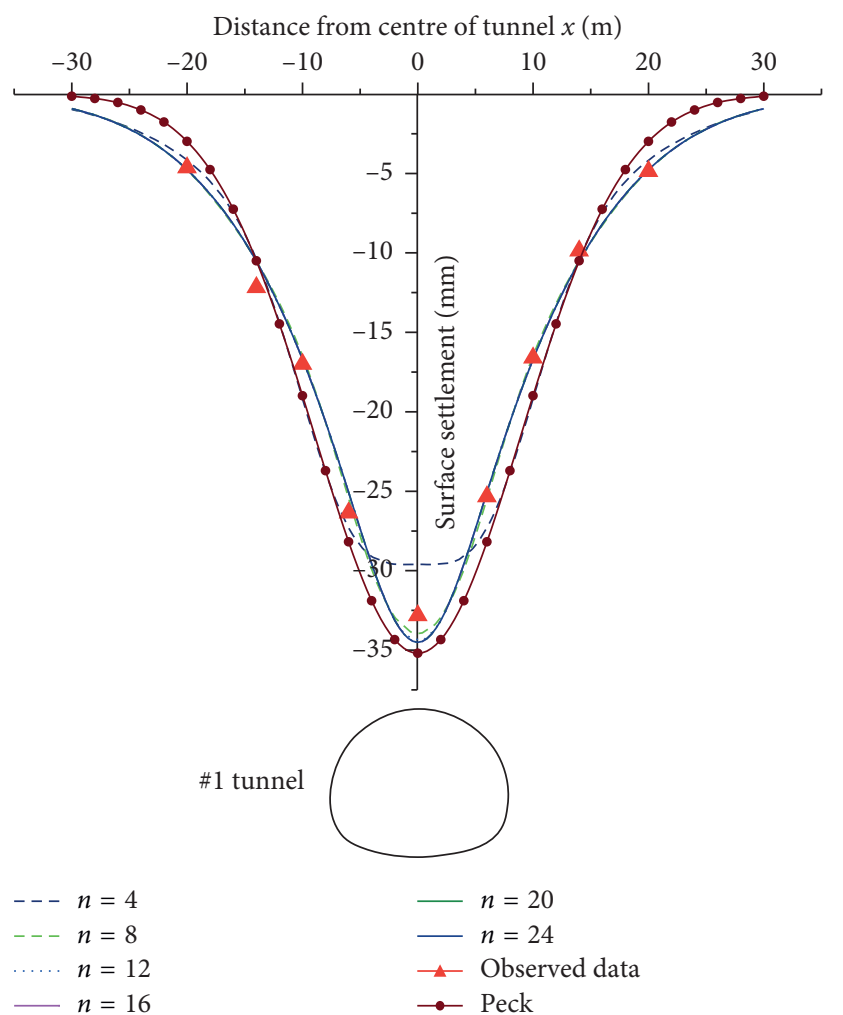

(a)

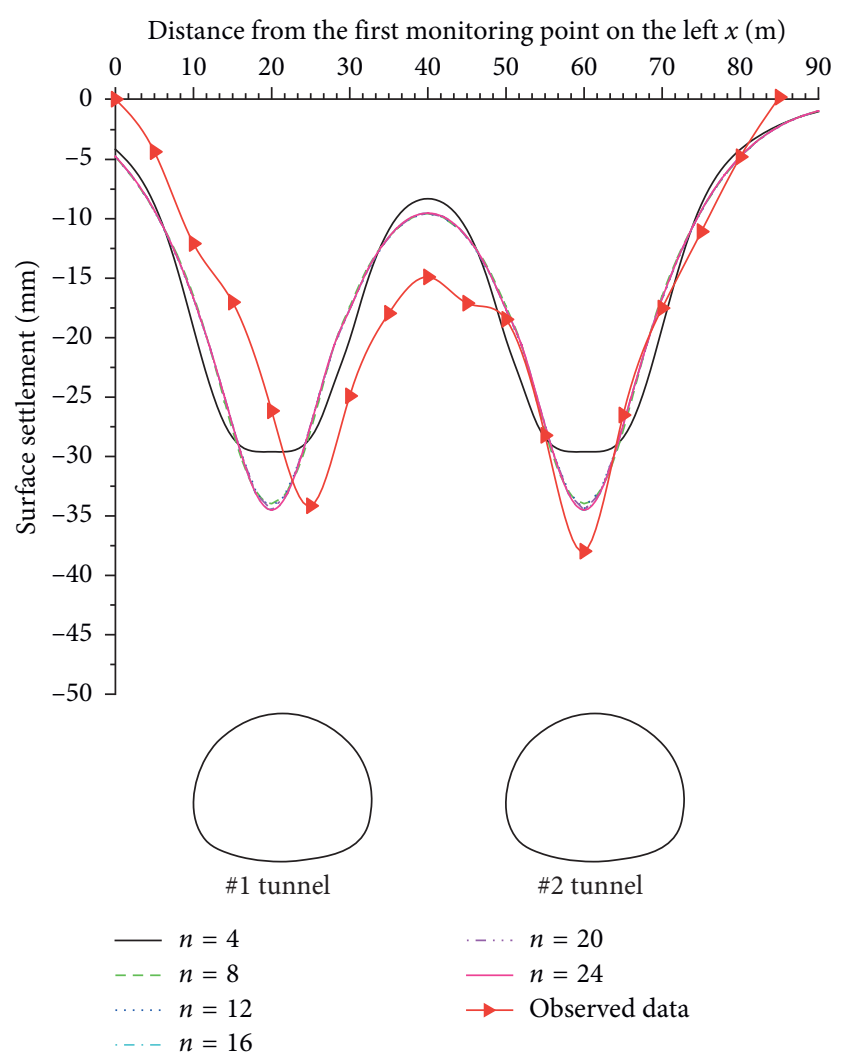

(b)

Figure 4: Surface settlement curves of different units. (a) \#1 tunnel. (b) \#2 tunnel.

Table 1: Parameters of different settlement curves (\#1 tunnel).

\begin{tabular}{lcccc}
\hline$n$ & $\begin{array}{c}\text { Width of settlement } \\
\text { trough } i(\mathrm{~m})\end{array}$ & $\begin{array}{c}\text { Maximum settlement } \\
S_{\max }(\mathrm{mm})\end{array}$ & $\begin{array}{c}\text { Relative error in } \\
\text { width of settlement trough (\%) }\end{array}$ & $\begin{array}{c}\text { Relative error in } \\
\text { maximum settlement (\%) }\end{array}$ \\
\hline 4 & 10.64 & -29.60 & 18.22 & -9.75 \\
8 & 9.27 & -33.96 & 3.00 & 3.54 \\
12 & 9.14 & -34.46 & 1.56 & 5.10 \\
16 & 9.13 & -34.51 & 1.44 & 5.21 \\
20 & 9.13 & -34.51 & 1.44 & 5.21 \\
24 & 9.13 & -34.51 & 1.44 & 5.21 \\
\hline
\end{tabular}

"-" in front of the maximum settlement indicates the vertically downward direction of the surface displacement. "-" in front of the maximum settlement relative error value indicates that the calculation value of the modified Peck formula is smaller than the calculation value of the Peck formula. "-" expresses the same meaning in the following tables.

settlement curve when $n=8$ differ greatly in the value of the maximum settlement, but the difference in the width of the settlement trough is not obvious. When the number of units $n$ increases from 8 , there is no significant change in either the width of the settlement trough or the value of the maximum settlement, and the settlement curve is nearly coincident.

Based on the analysis results of Table 1 and Figure 4(a), when the number $n=4$, the calculated maximum settlement value is smaller than the measured maximum settlement value $9.75 \%$, and when $n$ is greater than or equal to 8 , the calculated maximum settlement is 3.54\% 5.21\% larger than the observed maximum settlement. The maximum surface settlement calculated with the Peck formula was 9.15\% larger than the observed one, which indicates that the surface settlement calculated by the modified Peck formula is closer to the measured data and that the surface settlement calculated by the Peck formula has a significant error in the shallow-buried tunnel.

The surface settlement curve does not change when the $n$ value continues to increase. Therefore, for this project, when $n=8$ for the division of the over-excavation area, the calculation precision of the surface settlement curve obtained by using equation (9) can meet the accuracy of engineering estimation. Therefore, the engineering example also verified the rationality of the modified Peck formula based on the idea of stochastic medium theory, and there is a reasonable number of $n$ when the modified Peck formula is used to calculate surface settlement.

As can be seen from Figure 4(b), the surface settlement curve calculated by the modified Peck formula is consistent 


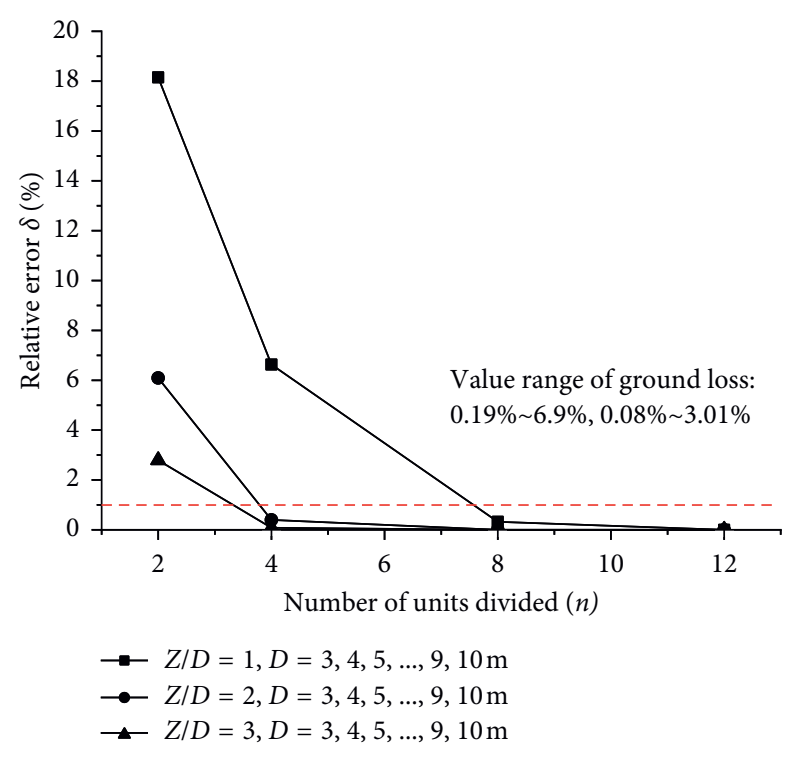

Figure 5: Trend of $\delta$ with $n$.

with the observed surface settlement curve after the excavation of \#2 tunnel. Affected by the construction of \#2 tunnel, the maximum observed settlement value of $\# 1$ tunnel does not appear above the tunnel crown, but on the right side of the tunnel crown. However, the maximum calculated value of \#1 tunnel is equal to the observed settlement. The observed surface settlement curve of $\# 2$ tunnel is consistent with the calculated settlement curve, but the maximum observed value of \#2 tunnel is 9.8\% larger than the calculated value. It shows that the modified Peck formula can better predict the surface settlement of singleline tunnel, but there will be some errors for the double-line tunnel.

\section{Analysis and Discussion}

5.1. Reasonable $n$ Values. According to the above case study, the higher the $n$ value is, the higher the calculation accuracy will be. However, the amount of calculation and the difficulty of calculation increase with the increase of $n$ value. The reasonable unit number $n$ is further discussed to meet the needs of engineering evaluation and to achieve the purpose of simple calculation. In this paper, the reasonable value of $n$ is presented in the clay and sand soil layers commonly encountered in the construction process of urban subway tunnels. The variation range of ground loss rate of clay is $0.19 \% \sim 6.9 \%$, that of sand is $0.08 \% \sim 3.01 \%$ [34], and the friction angle of soil is $30^{\circ}$. If the relative error $=1 \%$, the control condition of reasonably divided number $n$ is

$$
\delta=\frac{S_{(n+1) \cdot \max }-S_{n \cdot \max }}{S_{n \cdot \max }} \leq 1 \%,
$$

where $S_{n \cdot \max }$ and $S_{(n+1) \cdot \max }$ are the maximum settlement values when the number of units is divided into $n$ and $n+1$, respectively.

The variation trend of the relative error with the number of $n$ is shown in Figure 5 .

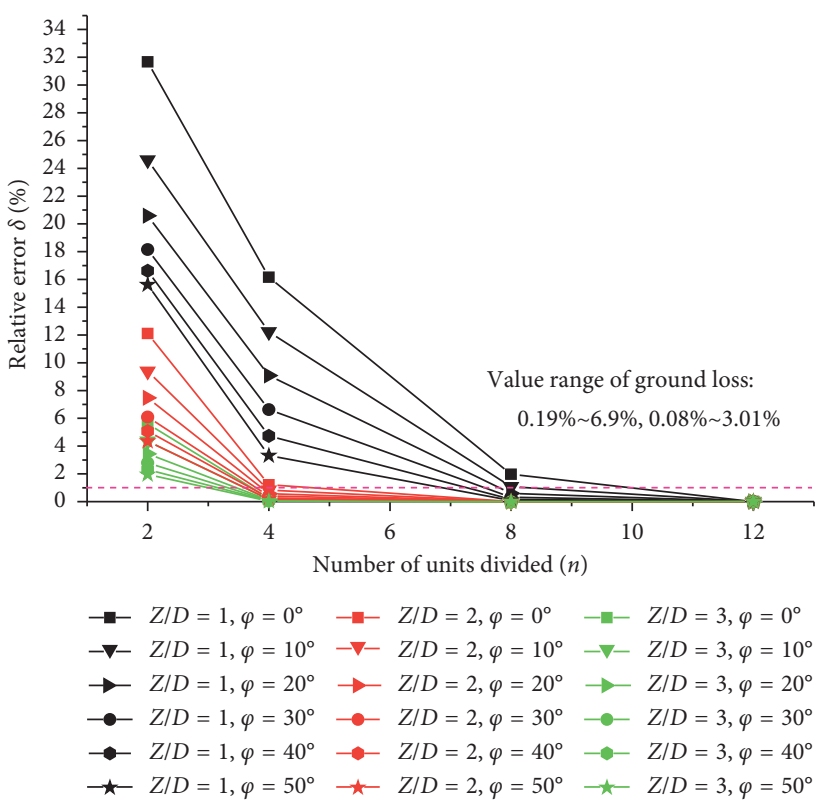

Figure 6: Trend of $\delta$ with $n$.

TABLE 2: Recommended value of $n$.

\begin{tabular}{lcc}
\hline & $0^{\circ}<\varphi<10^{\circ}$ & $\varphi>10^{\circ}$ \\
\hline$Z / D<2$ & 10 & 8 \\
$Z / D>2$ & 4 & 4 \\
\hline
\end{tabular}

As can be seen from Figure 5, when the tunnel diameter ratio (the ratio of tunnel depth to the equivalent diameter of the tunnel $Z / D$ ) is constant, the relative error does not change with the diameter but decreases with the increase of the tunnel diameter ratio. It is also found that the relative error does not change with the formation loss. When the tunnel diameter ratio is greater than or equal to 2, the relative error is reduced to less than $1 \%$; only the overexcavation part needs to be divided into 4 units, which indicates the reasonable units $n=4$ under this condition. When the tunnel diameter ratio is less than 2 , to reduce the relative error to less than $1 \%$, the over-excavation part needs to be divided into 8 units, indicating the reasonable division unit number $n=8$ under this condition.

The urban subway tunnel passes through various soil layers in the construction process. Different $\varphi$ values represent various soil layers; the obtained relative error $\delta$ with the $n$ change trend is shown in Figure 6.

5.2. Comparison of the Modified Peck Formula and Peck Formula. To further analyse and verify the rationality of the modified Peck formula, we took urban subway construction as the engineering background and compared the differences of the surface settlement curves calculated by the modified Peck formula and Peck formula under different tunnel depth, soil internal friction angle, and ground loss rate conditions. Tunnel Depths. To further analyse and verify the rationality 


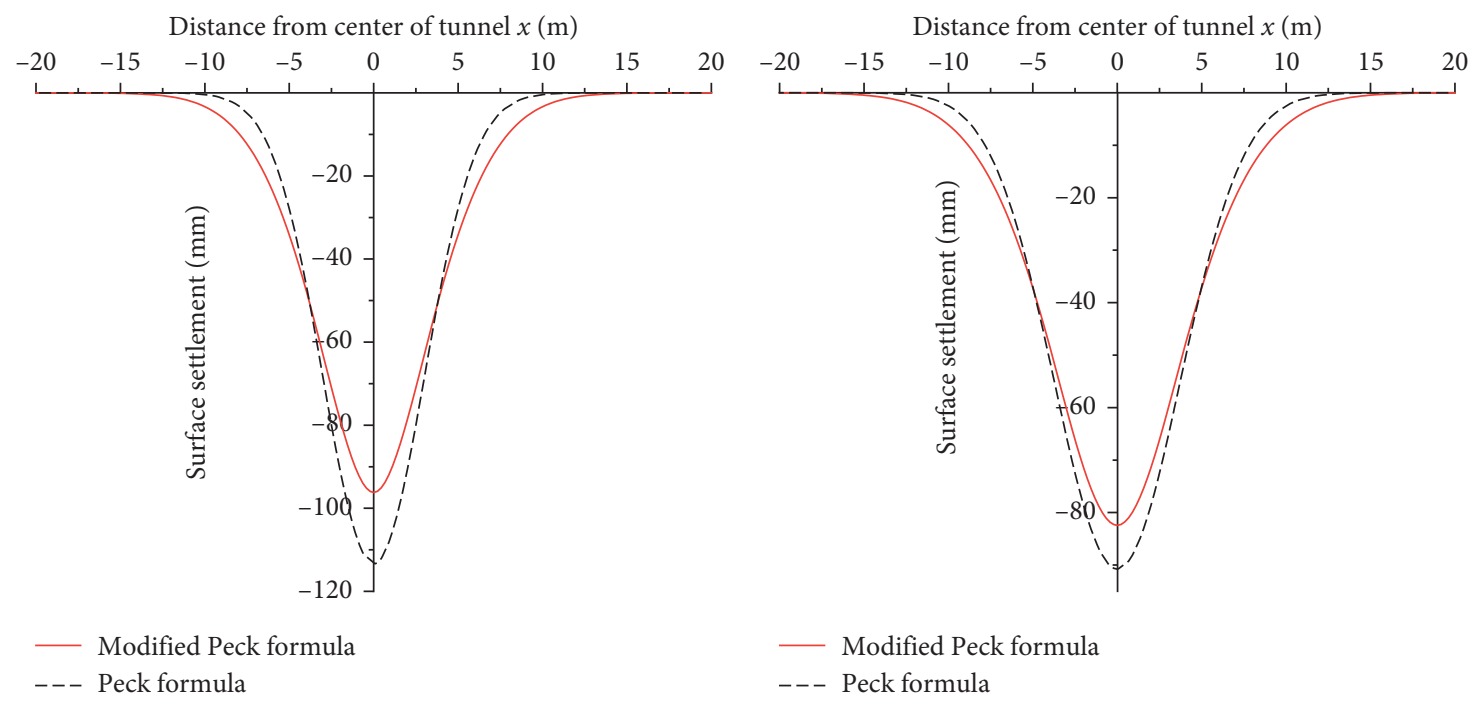

(a)

(b)

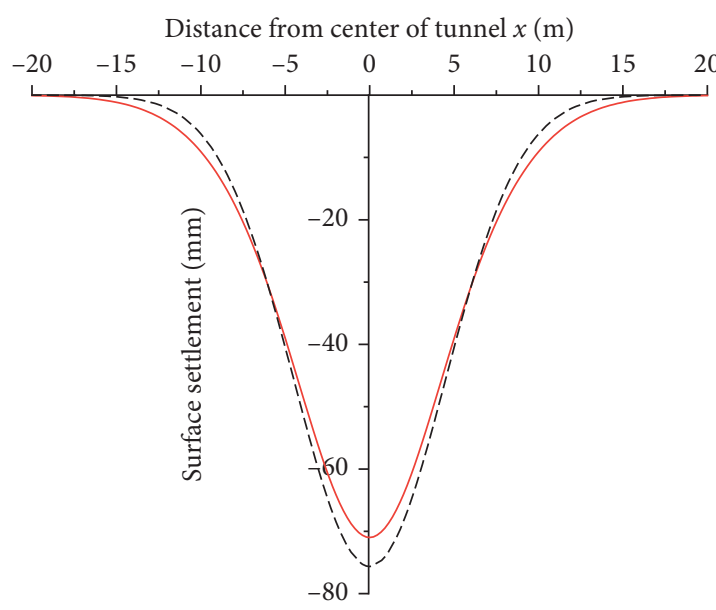

_ Modified Peck formula

— Modified Peck formul

- - Peck formula

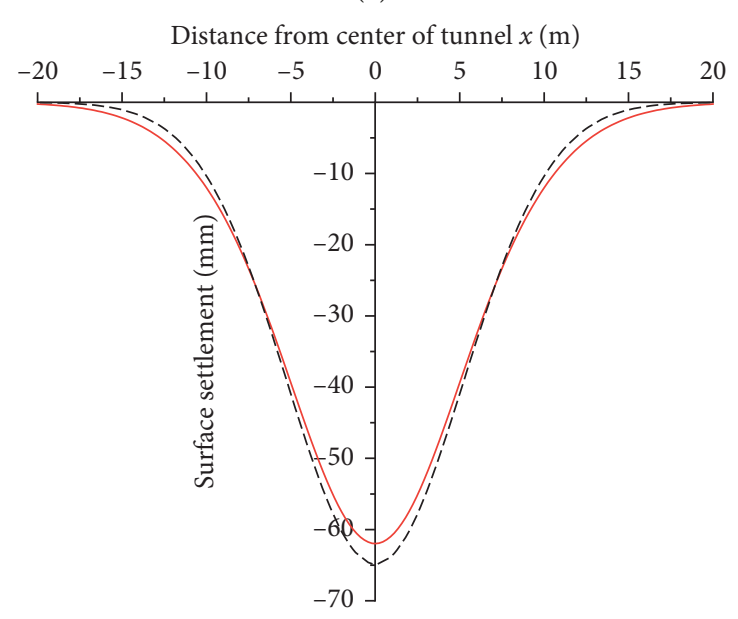

— Modified Peck formula

--- Peck formula

(c)

(d)

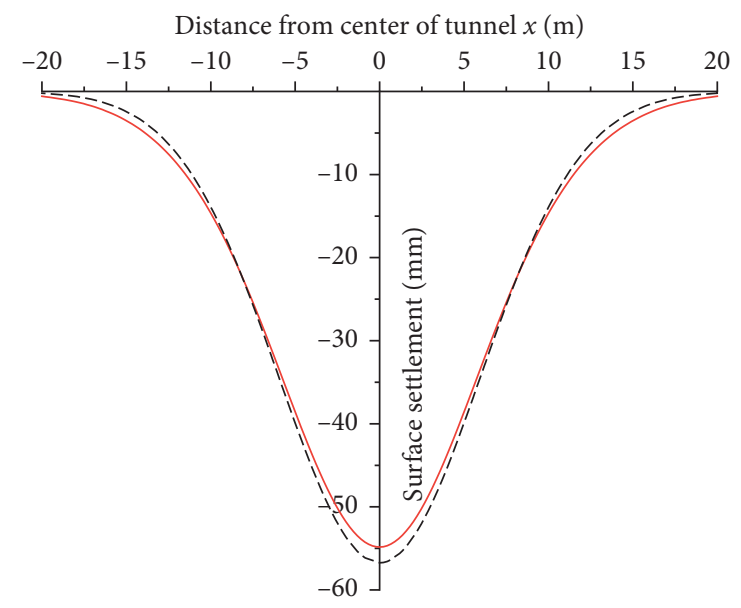

— Modified Peck formula

- - - Peck formula

(e)

FIGURE 7: Comparison of calculation results of surface settlement curves of different tunnel depths: (a) $Z=6 \mathrm{~m}$; (b) $Z=7.5 \mathrm{~m}$; (c) $Z=9 \mathrm{~m}$; (d) $Z=10.5 \mathrm{~m}$; (e) $Z=12 \mathrm{~m}$. 
TABLE 3: The relevant parameters of the settlement curve of each tunnel depth $Z$.

\begin{tabular}{|c|c|c|c|c|c|}
\hline Calculation method & $\begin{array}{c}Z \\
(\mathrm{~m})\end{array}$ & $\begin{array}{c}i \\
(\mathrm{~m})\end{array}$ & $\begin{array}{c}S_{\max } \\
(\mathrm{mm})\end{array}$ & $\begin{array}{l}\text { Relative error in width of settlement trough } \\
(\%)\end{array}$ & $\begin{array}{c}\text { Relative error in maximum settlement } \\
(\%)\end{array}$ \\
\hline $\begin{array}{l}\text { The modified Peck } \\
\text { formula }\end{array}$ & \multirow[t]{2}{*}{6} & 3.52 & & \multirow[t]{2}{*}{18.0} & \multirow[t]{2}{*}{-15.22} \\
\hline Peck formula & & 2.98 & -113.46 & & \\
\hline $\begin{array}{l}\text { The modified Peck } \\
\text { formula }\end{array}$ & \multirow{2}{*}{7.5} & 4.10 & -82.44 & \multirow{2}{*}{10.1} & \multirow{2}{*}{-9.18} \\
\hline Peck formula & & 3.73 & -90.77 & & \\
\hline $\begin{array}{l}\text { The modified Peck } \\
\text { formula }\end{array}$ & \multirow[t]{2}{*}{9} & 4.83 & -70.98 & \multirow[t]{2}{*}{6.6} & \multirow[t]{2}{*}{-6.16} \\
\hline Peck formula & & 4.47 & -75.64 & & \\
\hline $\begin{array}{l}\text { The modified Peck } \\
\text { formula }\end{array}$ & \multirow[t]{2}{*}{10.5} & 5.46 & -61.96 & \multirow[t]{2}{*}{4.6} & \multirow{2}{*}{-4.44} \\
\hline Peck formula & & 5.22 & -64.84 & & \\
\hline $\begin{array}{l}\text { The modified Peck } \\
\text { formula }\end{array}$ & \multirow[t]{2}{*}{12} & 6.17 & -54.83 & \multirow[t]{2}{*}{3.4} & \multirow[t]{2}{*}{-3.35} \\
\hline Peck formula & & 5.96 & -56.73 & & \\
\hline
\end{tabular}

and feasibility of the modified Peck formula, the paper took the urban subway construction in the soft and clay soil layer as the engineering background and compared and analysed the differences of the surface settlement curves calculated by the modified Peck formula and Peck formula under different tunnel buried depth conditions. Based on the comparative analysis and discussion, the applicable range of the Peck formula for engineering allowable error range is discussed.

Tunnel diameter is $6.0 \mathrm{~m}$, the ground loss rate is $3.0 \%$, and the internal friction angle of soil is $12.5^{\circ}$. The overexcavation part of the tunnel is divided into 8 units, and the surface settlement curves at the tunnel depth of $6.0 \mathrm{~m}, 7.5 \mathrm{~m}$, $9.0 \mathrm{~m}, 10.5 \mathrm{~m}$, and $12.0 \mathrm{~m}$ are calculated, respectively. Table 2 shows the modified Peck formula and Peck formula to calculate the parameters of the surface settlement curve at different tunnel depths. Figures 7(a)-7(e), respectively, show the settlement curves obtained by two calculation formulas at different tunnel depths.

According to Table 3 and Figure 7, the maximum settlement calculated by the Peck method is larger than that obtained by the modified Peck formula, but the width of the settlement trough calculated by the modified Peck formula was smaller than that obtained by the Peck formula. The settlement curve calculated by the Peck formula is broader and shallower than that achieved by the modified formula. With the increase of the tunnel depth, the surface settlement curve tends to be broad and shallow. As for the width of the settlement trough, the relative error between Peck formula and the modified formula is $18.0 \%$ when the tunnel depth was $6.0 \mathrm{~m}$. When the tunnel depth is $9.0 \mathrm{~m}$, the relative error is reduced to $6.16 \%$. When the tunnel depth increases to $12 \mathrm{~m}$, the relative error decreases to $3.35 \%$.

Therefore, the curve calculated by the Peck formula is more and more similar to the settlement curve calculated by the modified formula, and the value of the maximum settlement and the width of the settlement trough are also more and more similar. However, the surface settlement calculated by the Peck formula has a large error in the tunnel diameter ratio less than 1.75, which also shows that the Peck method is not suitable for the shallowburied tunnel. These results are similar to those of Han et al. [32].

\subsubsection{Comparison of Surface Settlement Curves with Different} Internal Friction Angles. The tunnel diameter is $6.0 \mathrm{~m}$, the ground loss rate is set at 3.0\%, and the tunnel depth is $6.0 \mathrm{~m}$. The over-excavation part of the tunnel is divided into 8 units, and the surface settlement curves of the soils with friction angles of $0^{\circ}, 10^{\circ}, 2^{\circ}, 30^{\circ}, 40^{\circ}, 50^{\circ}$, and $60^{\circ}$ are calculated, respectively. Table 4 shows the modified formula and the Peck formula to estimate the parameters of the surface settlement curve at different internal friction angles. Figures 8(a)-8(f), respectively, shows the comparison of settlement curves obtained by the two formulas at different internal friction angles.

According to Table 3 and Figure 8, the maximum settlement value and settlement trough width calculated by the Peck formula and the modified Peck formula both increase with the increase of internal friction angle. When the internal friction angle $0^{\circ} \sim 30^{\circ}$, the maximum settlement and the width of the settlement trough calculated by the modified Peck formula are smaller than the Peck formula, and the relative error of the two decreases with the increase of the internal friction angle. When the internal friction angle is $30^{\circ}$, the relative error between them is the smallest. When the internal friction angle is $30^{\circ} \sim 50^{\circ}$, the maximum settlement and the width of the settlement trough calculated by the modified Peck formula are larger than the Peck formula, and the relative error between them increases with the increase of the internal friction angle.

According to the above analysis, when the internal angle friction is about $30^{\circ}$, the settlement curve obtained by the Peck formula and the modified Peck formula is equal. It also shows that the modified Peck formula is more sensitive to 
TABLE 4: The relevant parameters of the settlement curve of each internal friction angles $\varphi$.

\begin{tabular}{|c|c|c|c|c|c|}
\hline Calculation method & $\begin{array}{l}\varphi \\
\left({ }^{\circ}\right)\end{array}$ & $\begin{array}{c}i \\
(\mathrm{~m})\end{array}$ & $\begin{array}{c}S_{\max } \\
(\mathrm{mm})\end{array}$ & $\begin{array}{l}\text { Relative error in width of settlement trough } \\
(\%)\end{array}$ & $\begin{array}{c}\text { Relative error in maximum settlement } \\
(\%)\end{array}$ \\
\hline $\begin{array}{l}\text { The modified Peck } \\
\text { formula }\end{array}$ & \multirow[t]{2}{*}{0} & 3.32 & -102.00 & \multirow[t]{2}{*}{38.61} & \multirow[t]{2}{*}{-27.85} \\
\hline Peck formula & & 2.39 & -141.37 & & \\
\hline $\begin{array}{l}\text { The modified Peck } \\
\text { formula }\end{array}$ & \multirow[t]{2}{*}{10} & 3.47 & -97.59 & \multirow[t]{2}{*}{21.55} & \multirow[t]{2}{*}{-17.73} \\
\hline Peck formula & & 2.85 & -118.62 & & \\
\hline $\begin{array}{l}\text { The modified Peck } \\
\text { formula }\end{array}$ & \multirow[t]{2}{*}{20} & 3.76 & -90.00 & \multirow[t]{2}{*}{9.99} & \multirow[t]{2}{*}{-9.08} \\
\hline Peck formula & & 3.42 & -98.99 & & \\
\hline $\begin{array}{l}\text { The modified Peck } \\
\text { formula }\end{array}$ & \multirow[t]{2}{*}{30} & 4.23 & -80.09 & \multirow[t]{2}{*}{1.91} & \multirow[t]{2}{*}{-1.88} \\
\hline Peck formula & & 4.15 & -81.62 & & \\
\hline $\begin{array}{l}\text { The modified Peck } \\
\text { formula }\end{array}$ & \multirow[t]{2}{*}{40} & 4.94 & -68.54 & \multirow[t]{2}{*}{-3.82} & \multirow[t]{2}{*}{3.97} \\
\hline Peck formula & & 5.13 & -65.92 & & \\
\hline $\begin{array}{l}\text { The modified Peck } \\
\text { formula }\end{array}$ & \multirow[t]{2}{*}{50} & 6.06 & -55.86 & \multirow[t]{2}{*}{-7.89} & \multirow[t]{2}{*}{8.57} \\
\hline Peck formula & & 6.58 & -51.46 & & \\
\hline
\end{tabular}

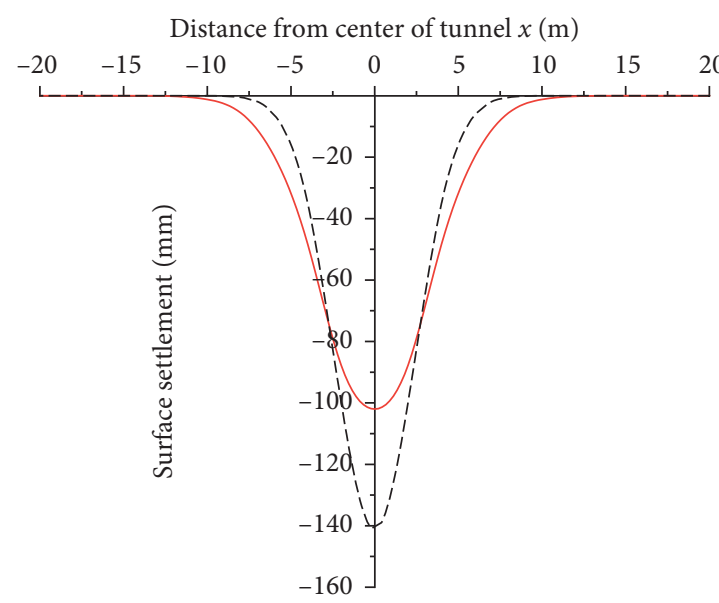

- Modified Peck formula

--- Peck formula
Distance from center of tunnel $x(\mathrm{~m})$

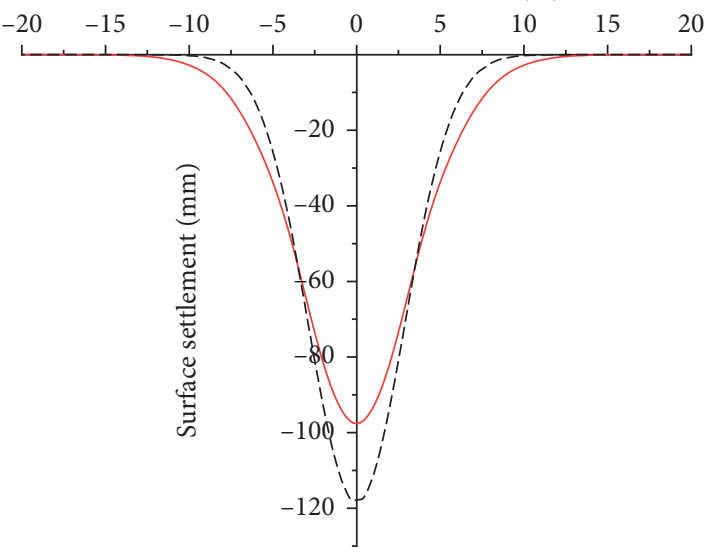

- Modified Peck formula

--- Peck formula

(a)

(b)

FIgURE 8: Continued. 

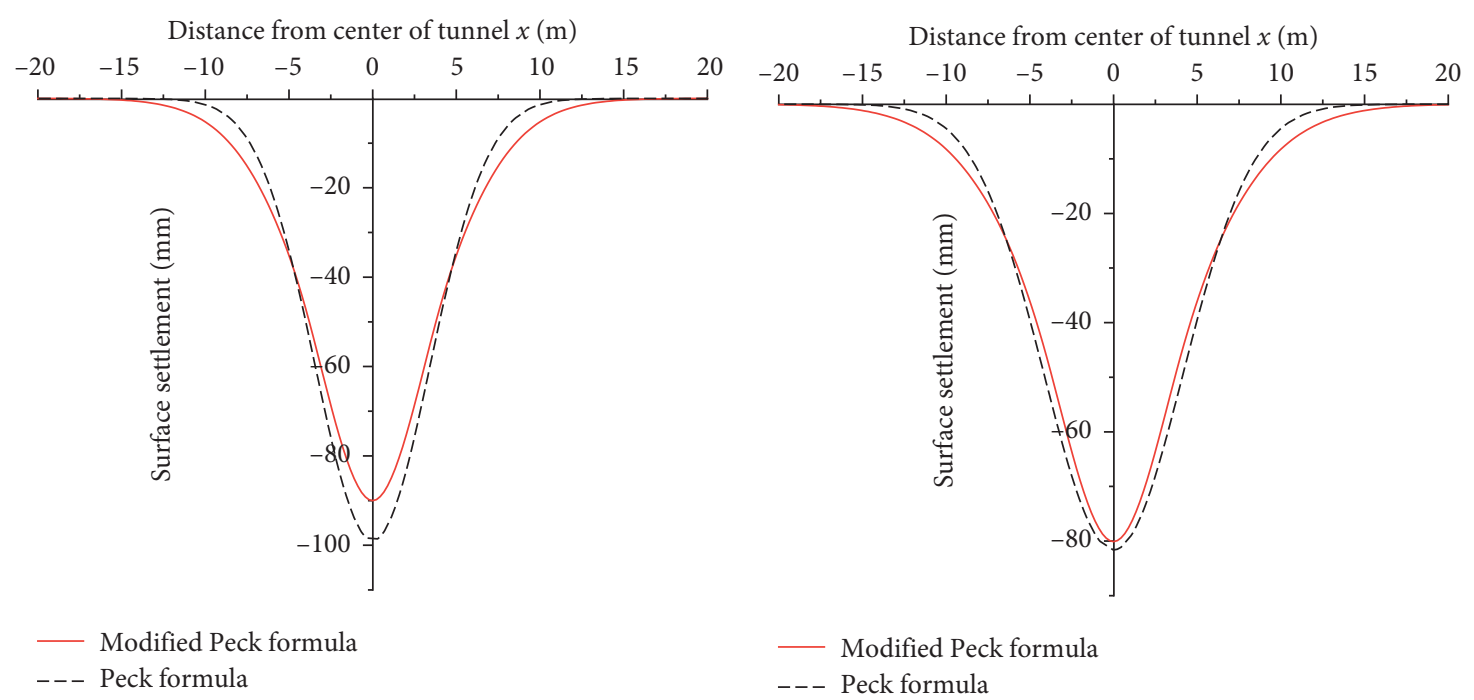

(c)

(d)

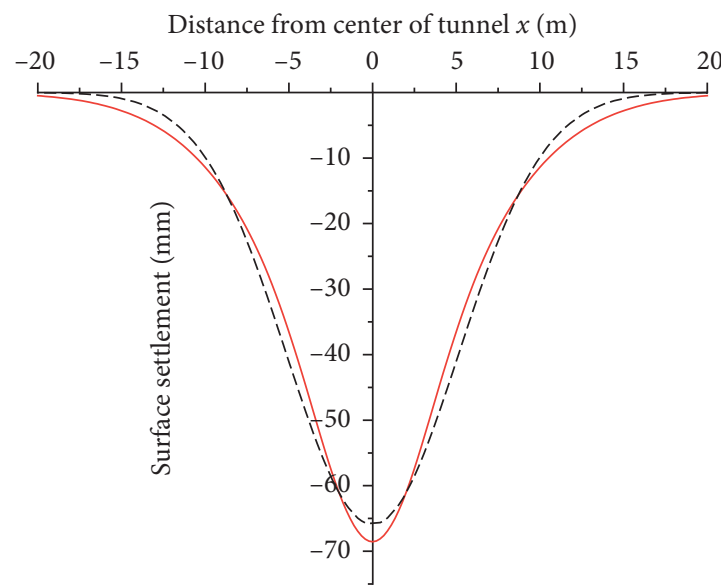

- Modified Peck formula
- - Peck formula

(e)
Distance from center of tunnel $x(\mathrm{~m})$

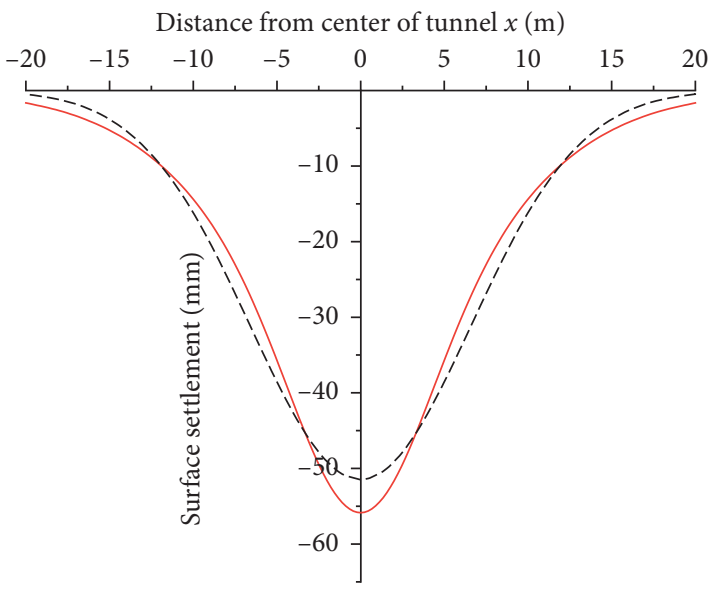

— Modified Peck formula

--- Peck formula

(f)

Figure 8: Comparison of surface settlement curves with different internal friction angles: (a) $\varphi=0^{\circ}$; (b) $\varphi=10^{\circ}$; (c) $\varphi=20^{\circ}$; (d) $\varphi=30^{\circ}$; (e) $\varphi=40^{\circ}$; (f) $\varphi=50^{\circ}$.

the friction angle. Therefore, when the internal angle friction is about $30^{\circ}$, this paper suggests using the Peck formula or the modified Peck formula to calculate the surface settlement. When internal angle friction is less than $20^{\circ}$ or greater than $40^{\circ}$, the modified Peck formula is adopted to calculate the surface settlement.

5.2.3. Comparison of Surface Settlement Curves with a Different Ground Loss Rates. The tunnel diameter is $6.0 \mathrm{~m}$, the internal friction angle is $12.5^{\circ}$, and the tunnel depth is $6.0 \mathrm{~m}$. The over-excavation part of the tunnel is divided into 8 units, and the surface settlement curves when the ground loss rate is $1.0 \%, 2.0 \%, 3.0 \%, 4.0 \%, 5.0 \%$, and $6.0 \%$ are calculated, respectively. Table 5 shows the modified formula and the Peck formula to estimate the parameters of the surface settlement curve under different bottom loss rates.
Figures 9(a)-9(f), respectively, shows the comparison of settlement curves under different ground loss rates under two calculation formulas.

According to Table 5 and Figure 9, the maximum settlement calculated by the modified Peck formula was smaller than that of the Peck formula. The maximum settlement calculated by the Peck formula and the modified Peck formula increases with the increase of ground loss rate, but the width of the settlement trough hardly changed. The relative error between the maximum settlement and the width of the settlement trough calculated by the two methods hardly changed with the increase of formation loss rate. It shows that when the tunnel diameter ratio and the internal friction angle of the soil are constant, the relative errors of the two methods are also constant, and the width of the settlement trough will not change the settlement value. 
TABLE 5: The relevant parameters of settlement curve of each ground loss rate $v_{l}$.

\begin{tabular}{|c|c|c|c|c|c|}
\hline Calculation method & $\begin{array}{c}v_{l} \\
(\%)\end{array}$ & $\begin{array}{c}i \\
(\mathrm{~m})\end{array}$ & $\begin{array}{l}S_{\max } \\
(\mathrm{mm})\end{array}$ & $\begin{array}{l}\text { Relative error in width of settlement trough } \\
(\%)\end{array}$ & $\begin{array}{l}\text { Relative error in maximum settlement } \\
(\%)\end{array}$ \\
\hline $\begin{array}{l}\text { The modified Peck } \\
\text { formula } \\
\text { Peck formula }\end{array}$ & 1.0 & $\begin{array}{l}3.54 \\
2.98\end{array}$ & $\begin{array}{l}-31.83 \\
-37.82\end{array}$ & 18.83 & -15.85 \\
\hline $\begin{array}{l}\text { The modified Peck } \\
\text { formula } \\
\text { Peck formula }\end{array}$ & 2.0 & $\begin{array}{l}3.54 \\
2.98\end{array}$ & $\begin{array}{r}-63.81 \\
-75.64 \\
\end{array}$ & 18.83 & -15.64 \\
\hline $\begin{array}{l}\text { The modified Peck } \\
\text { formula } \\
\text { Peck formula }\end{array}$ & 3.0 & $\begin{array}{l}3.53 \\
2.98\end{array}$ & $\begin{array}{r}-95.96 \\
-113.46 \\
\end{array}$ & 18.24 & -15.43 \\
\hline $\begin{array}{l}\text { The modified Peck } \\
\text { formula } \\
\text { Peck formula }\end{array}$ & 4.0 & $\begin{array}{l}3.52 \\
2.98 \\
\end{array}$ & $\begin{array}{r}-128.26 \\
-151.28 \\
\end{array}$ & 17.95 & -15.22 \\
\hline $\begin{array}{l}\text { The modified Peck } \\
\text { formula } \\
\text { Peck formula }\end{array}$ & 5.0 & $\begin{array}{l}3.51 \\
2.98\end{array}$ & $\begin{array}{l}-160.72 \\
-189.10 \\
\end{array}$ & 17.66 & -15.01 \\
\hline $\begin{array}{l}\text { The modified Peck } \\
\text { formula } \\
\text { Peck formula }\end{array}$ & 6.0 & $\begin{array}{l}3.50 \\
2.98 \\
\end{array}$ & $\begin{array}{l}-193.35 \\
-226.93 \\
\end{array}$ & 17.37 & -14.80 \\
\hline
\end{tabular}

Distance from center of tunnel $x(\mathrm{~m})$

Distance from center of tunnel $x(\mathrm{~m})$

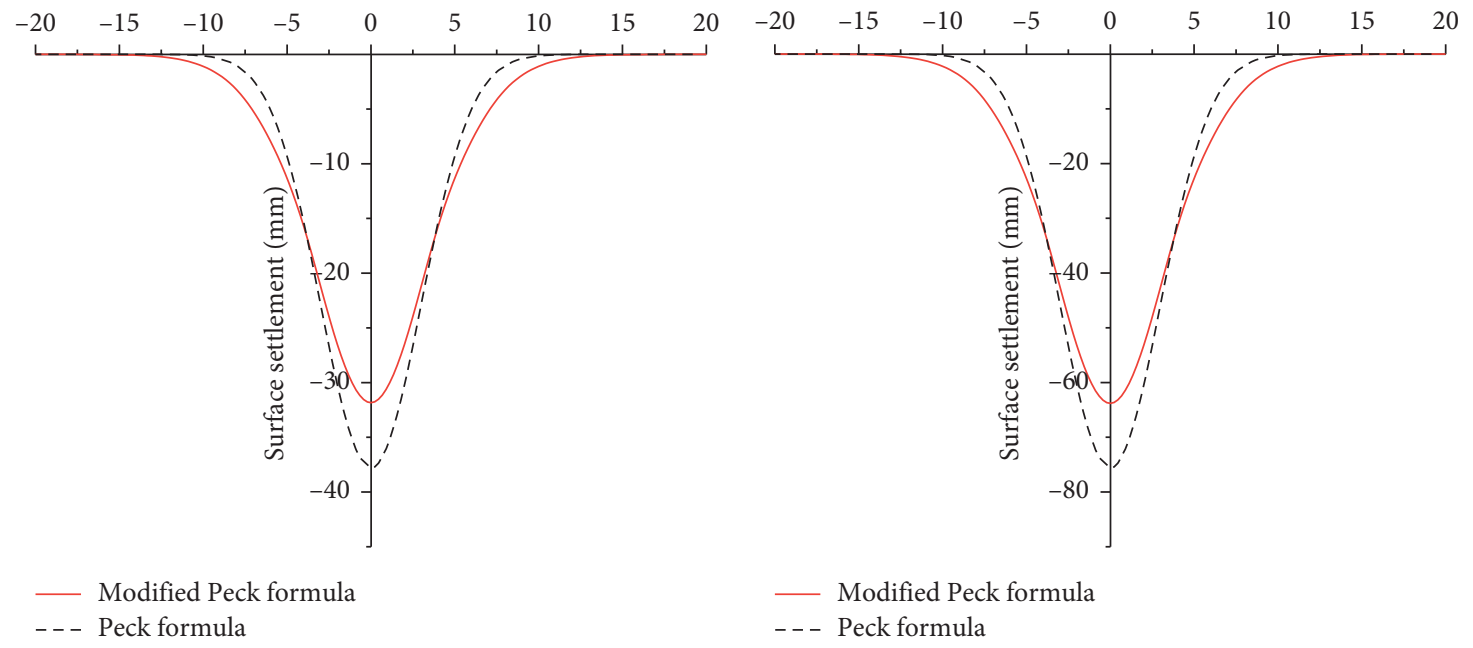

(a)

(b)

Figure 9: Continued. 
Distance from center of tunnel $x(\mathrm{~m})$

Distance from center of tunnel $x(\mathrm{~m})$

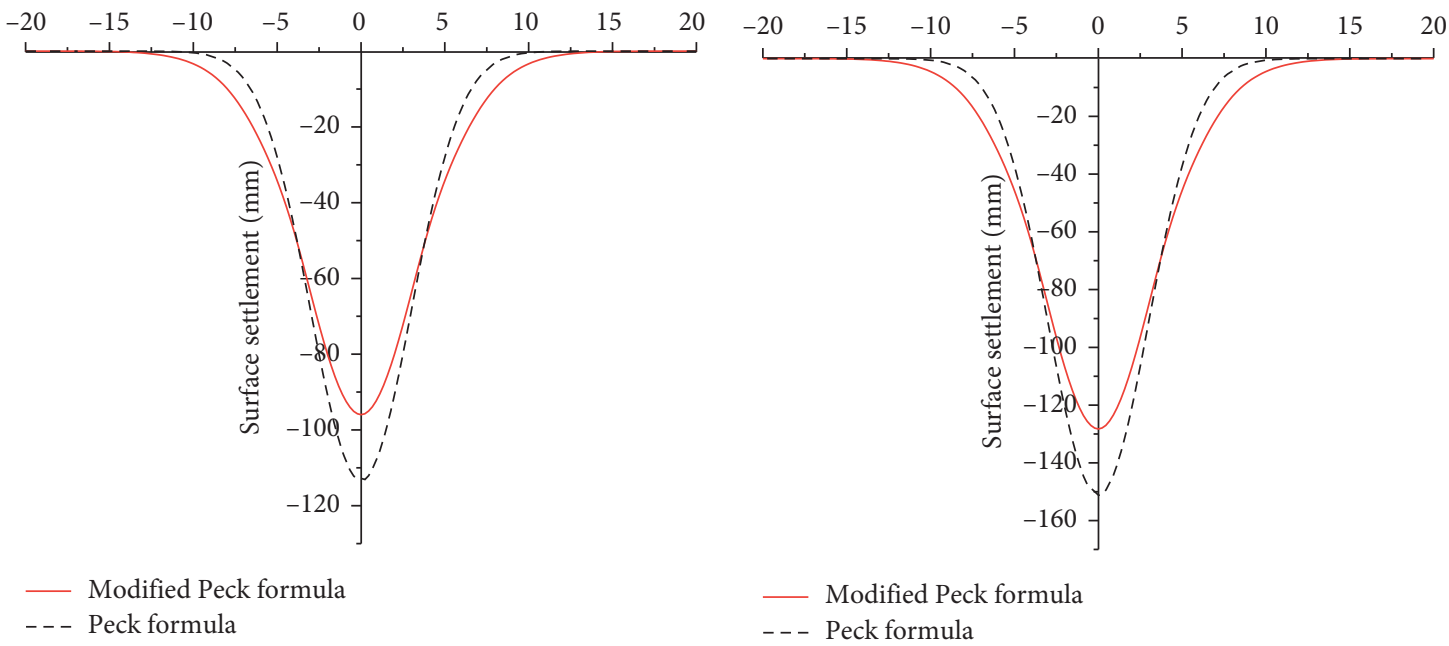

(c)

(d)

Distance from center of tunnel $x(\mathrm{~m})$

Distance from center of tunnel $x(\mathrm{~m})$
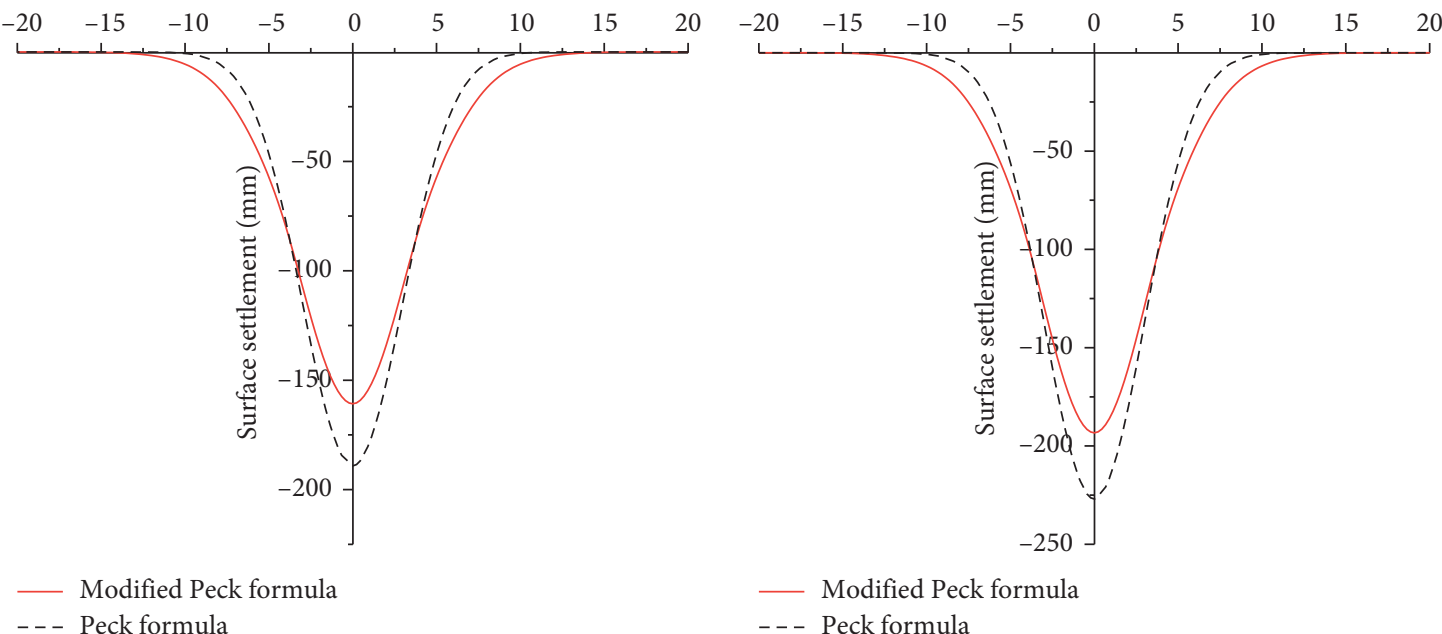

(e)

(f)

Figure 9: Comparison of calculation results of surface settlement curves for different ground loss rates: (a) $v_{l}=1 \%$; (b) $v_{l}=2 \%$; (c) $v_{l}=3 \%$; (d) $v_{l}=4 \%$; (e) $v_{l}=5 \%$; (f) $v_{l}=6 \%$.

\section{Conclusions}

The Peck method was not suitable for shallow-buried tunnels, and the calculation process of the stochastic medium theory was complicated. To address this problem, in this study, a simple and accurate prediction method for surface settlement was obtained by improving Peck method based on the basic idea of stochastic medium theory. The modified Peck formula was verified by an engineering example. The obtained conclusions are summarised as follows:

(1) The Peck formula is an approximate algorithm of the stochastic medium theory under the condition of large depth and a small section of the tunnel by comparing the calculation principle of surface settlement with the stochastic medium theory and the Peck formula.
(2) The case study indicated that the surface settlement calculated by the modified Peck formula is closer to the measured data than that calculated by the original Peck formula. It also showed that the modified Peck formula could better predict the surface settlement of single-line tunnel, but there will be some errors for the double-line tunnel.

(3) The reasonable number of $n$ does not change with the change of tunnel diameter when the tunnel diameter ratio is constant. With the control condition of the relative error is equal to $1 \%$, the reasonable number of $n$ with the tunnel diameter greater than or equal to 2 for the soil layer of whatever nature is equal to 4 . When the tunnel diameter ratio is less than 2 , the internal friction angle is greater than or equal to $0^{\circ}$ and less than or equal to $10^{\circ}$; the reasonable unit 
number $n$ equals 8. Meanwhile, internal friction angle $\varphi$ is more than $10^{\circ}$; the reasonable unit number is equal to 10 .

(4) The change rule of surface settlement is consistent under the tunnel depth, internal friction angle, and ground loss of the tunnel through comparing the surface settlement curve calculated by the modified Peck formula and Peck formula. However, the calculation error of the surface settlements calculated by the original Peck formula is larger than the surface settlements calculated by the modified Peck formula under the tunnel diameter ratio being less than 1.75. The modified Peck formula is more suitable for calculating the surface settlement under internal angle friction being less than $20^{\circ}$ or greater than $40^{\circ}$.

\section{Data Availability}

The data used to support the findings of this study are available from the corresponding author upon request.

\section{Conflicts of Interest}

The authors declare that they have no conflicts of interest.

\section{Acknowledgments}

This work was subsidized and supported by the National Natural Science Foundation of China (No. 51578447), the Science and Technology Project of Ministry of Housing Urban-Rural Construction (No. 2017-K4-032), and the project funded by China Postdoctoral Science Foundation (No. 2018M643809XB). The financial supports are gratefully acknowledged by the authors.

\section{References}

[1] Z. Wang, W. Yao, Y. Cai, B. Xu, Y. Fu, and G. Wei, “Analysis of ground surface settlement induced by the construction of a large-diameter shallow-buried twin-tunnel in soft ground," Tunnelling and Underground Space Technology, vol. 83, pp. 520-532, 2019.

[2] Z. P. Song, S. H. Li, X. G. Zhang, J. B. Wang, and T. Wang, "Study on strata settlement regular pattern induced by tunnel construction based on Peck formula," Journal of Xi'an University of Architecture \& Technology (Natural Science Edition), vol. 50, no. 2, pp. 190-195, 2018.

[3] W.-C. Cheng, Z.-P. Song, W. Tian, and Z.-F. Wang, "Shield tunnel uplift and deformation characterisation: a case study from Zhengzhou metro," Tunnelling and Underground Space Technology, vol. 79, pp. 83-95, 2018.

[4] Y. W. Zhang, X. L. Weng, Z. P. Song, and Y. F. Sun, "Modeling of loess soaking induced impacts on metro tunnel using water soaking system in centrifuge," Geofluids, vol. 2019, Article ID 5487952, 17 pages, 2019, In press.

[5] Y. W. Zhang, Z. P. Song, X. L. Weng, and Y. L. Xie, "A new soil-water characteristic curve model for unsaturated loess based on wetting-induced pore deformation," Geofluids, vol. 2019, Article ID. 1672418, 14 pages, 2019, In press.

[6] Z. Zhang, M. Huang, C. Zhang, K. Jiang, and M. Lu, "Timedomain analyses for pile deformation induced by adjacent excavation considering influences of viscoelastic mechanism," Tunnelling and Underground Space Technology, vol. 85, no. 3, pp. 392-405, 2019.

[7] Z. Zhang, M. Huang, C. Xu, Y. Jiang, W. Wang, and W. Wang, "Simplified solution for tunnel-soil-pile interaction in Pasternak's foundation model," Tunnelling and Underground Space Technology, vol. 78, no. 8, pp. 146-158, 2018.

[8] M. Lei, D. Lin, Q. Huang, C. Shi, and L. Huang, "Research on the construction risk control technology of shield tunnel underneath an operational railway in sand pebble formation: a case study," European Journal of Environmental and Civil Engineering, vol. 2018, pp. 1-15, 2018.

[9] R. B. Peck, "Deep excavations and tunnelling in soft ground," in Proceedings of the Seventh International Conference on Soil Mechanics and Foundation Engineering, pp. 225-290, Mexico City, Mexico, August 1969.

[10] P. B. Attewell and J. P. Woodman, "Predicting the dynamics of ground settlement and its derivatives caused by tunneling in soil," International Journal of Rock Mechanics and Mining Sciences \& Geomechanics Abstracts, vol. 15, no. 8, pp. 13-22, 1982.

[11] R. J. Mair, R. N. Taylor, and A. Bracegirdle, "Subsurface settlement profiles above tunnels in clays," Géotechnique, vol. 45, no. 2, pp. 361-362, 1995.

[12] M. Lei, J. Liu, Y. Lin, C. Shi, and C. Liu, "Deformation characteristics and influence factors of a shallow tunnel excavated in soft clay with high plasticity," Advances in Civil Engineering, vol. 2019, Article ID 7483628, 14 pages, 2019.

[13] C. Sagaseta, "Analysis of undraind soil deformation due to ground loss," Géotechnique, vol. 37, no. 3, pp. 301-320, 1987.

[14] A. Verruijt and J. R. Booker, "Surface settlements due to deformation of a tunnel in an elastic half plane," Géotechnique, vol. 46, no. 4, pp. 753-756, 1996.

[15] N. Loganathan and H. G. Poulos, "Analytical prediction for tunneling-induced ground movements in clays," Journal of Geotechnical and Geoenvironmental Engineering, vol. 124, no. 9, pp. 846-856, 1998.

[16] B. Zeng, D. Huang, and J. He, "Analysis of double-O-tube shield tunnelling-induced soil deformation due to ground loss," Géotechnique Letters, vol. 6, no. 1, pp. 7-15, 2016.

[17] A. M. M. Wood, "The circular tunnel in elastic ground," Géotechnique, vol. 25, no. 1, pp. 115-127, 1975.

[18] A. Bobet, "Analytical solutions for shallow tunnels in saturated ground," Journal of Engineering Mechanics, vol. 127, no. 12, pp. 1258-1266, 2001.

[19] K. H. Park, "Elastic solution for tunneling-induced ground movements in clays," International Journal of Geomechanics, vol. 4, no. 4, pp. 310-318, 2004.

[20] K.-H. Park, "Analytical solution for tunnelling-induced ground movement in clays," Tunnelling and Underground Space Technology, vol. 20, no. 3, pp. 249-261, 2005.

[21] A. M. Puzrin, J. B. Burland, and J. R. Standing, "Simple approach to predicting ground displacements caused by tunnelling in undrained anisotropic elastic soil," Géotechnique, vol. 62, no. 4, pp. 341-352, 2012.

[22] J. Litwiniszyn, "The theories and model research of movements of ground masses," in Proceedings of the European Congress Ground Movement, pp. 203-209, Leeds, UK, April 1957.

[23] K. Wu, Z. S. Shao, S. Qin, and B. X. Li, "Determination of deformation mechanism and countermeasures in silty clay tunnel," Journal of Performance of Constructed Facilities, 2019. 
[24] X. L. Yang and J. M. Wang, "Ground movement prediction for tunnels using simplified procedure," Tunnelling and Underground Space Technology, vol. 26, no. 3, pp. 462-471, 2011.

[25] Y. Cheng, Z. Song, J. Jin, and T. Yang, "Attenuation characteristics of stress wave peak in sandstone subjected to different axial stresses," Advances in Materials Science and Engineering, vol. 2019, Article ID 6320601, 11 pages, 2019.

[26] G. Swoboda and A. Abu-Krisha, "Three-dimensional numerical modelling for TBM tunnelling in consolidated clay," Tunnelling and Underground Space Technology, vol. 14, no. 3, pp. 327-333, 1999.

[27] D. J. White, W. A. Take, and M. D. Bolton, "Soil deformation measurement using particle image velocimetry (PIV) and photogrammetry," Géotechnique, vol. 53, no. 7, pp. 619-631, 2003.

[28] G. Song and J. A. Black, "Soil Displacement due to tunnelling using small-scale centrifuge technology," in Proceedings of the 3rd European Conference on Physical Modelling in Geotechnics (ECPMG 2016), Nantes, France, June 2016.

[29] S. W. Jacobsz, J. R. Standing, R. J. Mair, T. Hagiwara, and T. Sugiyama, "Centrifuge modelling of tunnelling near driven piles," Soils and Foundations, vol. 44, no. 1, pp. 49-56, 2004.

[30] T. E. Vorster, A. Klar, K. Soga, and R. J. Mair, "Estimating the effects of tunneling on existing pipelines," Journal of Geotechnical and Geoenvironmental Engineering, vol. 131, no. 11, pp. 1399-1410, 2005.

[31] T. B. Celestino, R. A. M. P. Gomes, and A. A. Bortolucci, "Errors in ground distortions due to settlement trough adjustment," Tunnelling and Underground Space Technology, vol. 15, no. 1, pp. 97-100, 2000.

[32] X. Han, N. Li, and J. R. Standing, "An adaptability study of Gaussian equation applied to predicting of ground settlements induced by tunneling in China," Rock and Soil Mechanics, vol. 28, no. 1, pp. 23-39, 2007, in Chinese.

[33] B. C. Liu and J. S. Zhang, "Stochastic method for ground settlement due to near surface excavation," Chinese Journal of Rock Mechanics and Engineering, vol. 14, no. 4, pp. 289-296, 1995, in Chinese.

[34] J. S. Yang and B. C. Liu, "Ground surface movement and deformation due to tunnel construction by squeezing shield," Rock and Soil Mechanics, vol. 19, no. 3, pp. 10-13, 1998.

[35] C. Shi, C. Cao, and M. Lei, "An analysis of the ground deformation caused by shield tunnel construction combining an elastic half-space model and stochastic medium theory," KSCE Journal of Civil Engineering, vol. 21, no. 5, pp. 19331944, 2017.

[36] A. Franza and M. A. Marshall, "Empirical and semi-analytical methods for evaluating tunnelling-induced ground movements in sands," Tunnelling and Underground Space Technology, vol. 88, pp. 47-62, 2019.

[37] X. Z. Li, S. C. Li, and S. C. Li, "Ground settlement deformation characteristic study of shallow large-span tunnel in construction process," Chinese Journal of Rock Mechanics and Engineering, vol. 30, no. S1, pp. 3348-3353, 2011, in Chinese.

[38] C. H. Zhu and N. Li, "Estimation method and laws analysis of surface settlement due to tunneling," Rock and Soil Mechanics, vol. 38, no. S2, pp. 533-542, 2016, in Chinese.

[39] China Railway Eryuan Engineering Group Co. Ltd., Code for Design of Railway Tunnel, China Railway Publishing House, Beijing, China, 2016. 


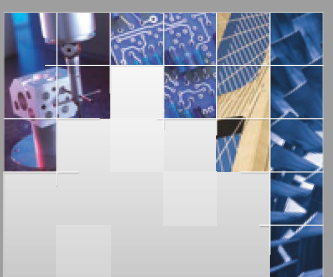

\section{Enfincering}
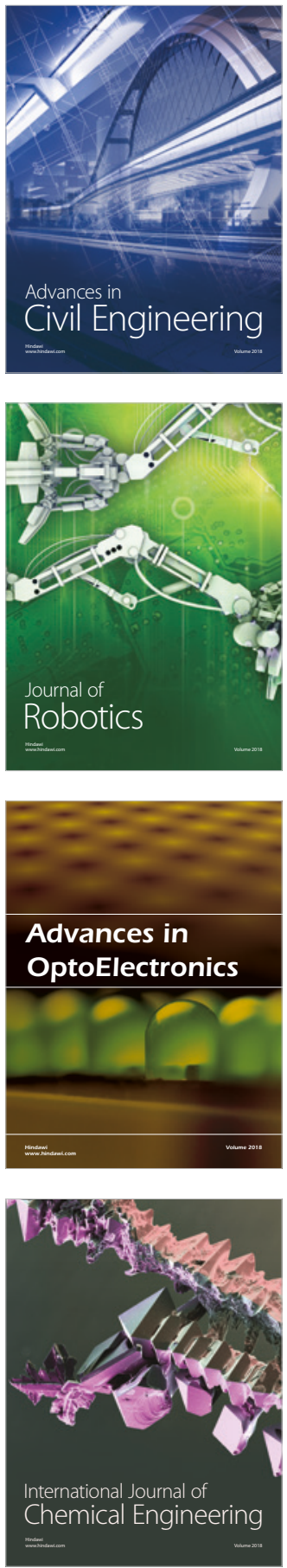

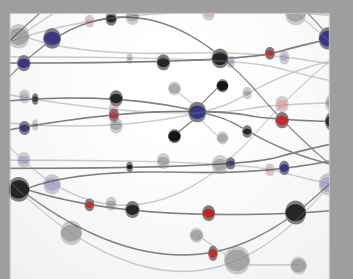

\section{Rotating \\ Machinery}

The Scientific World Journal

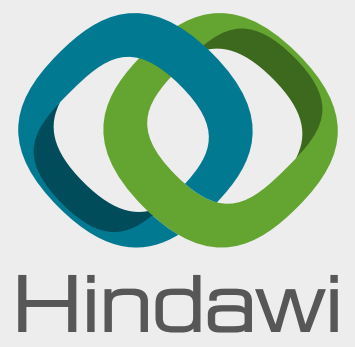

Submit your manuscripts at

www.hindawi.com
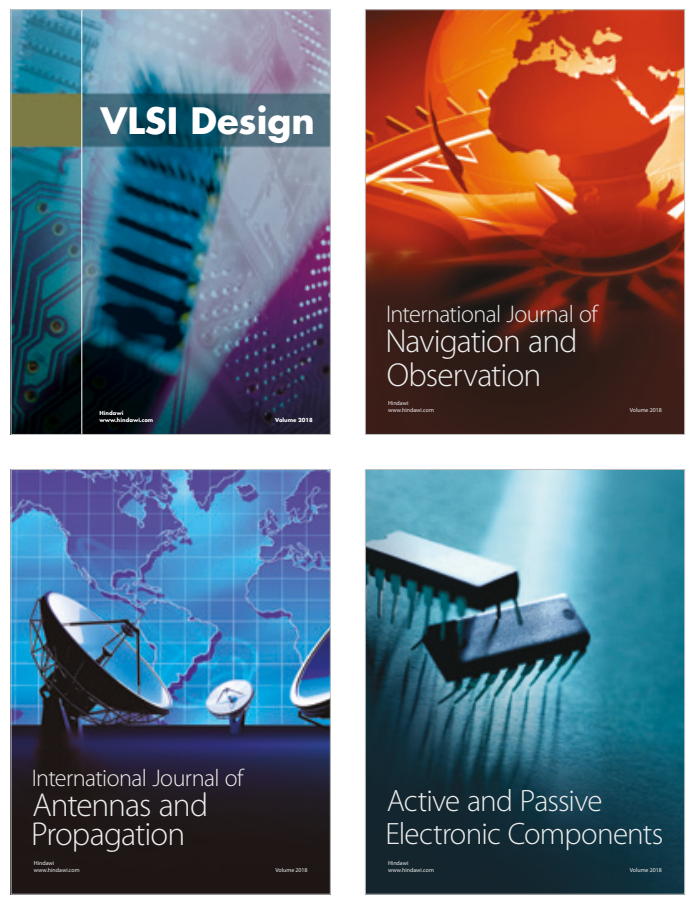
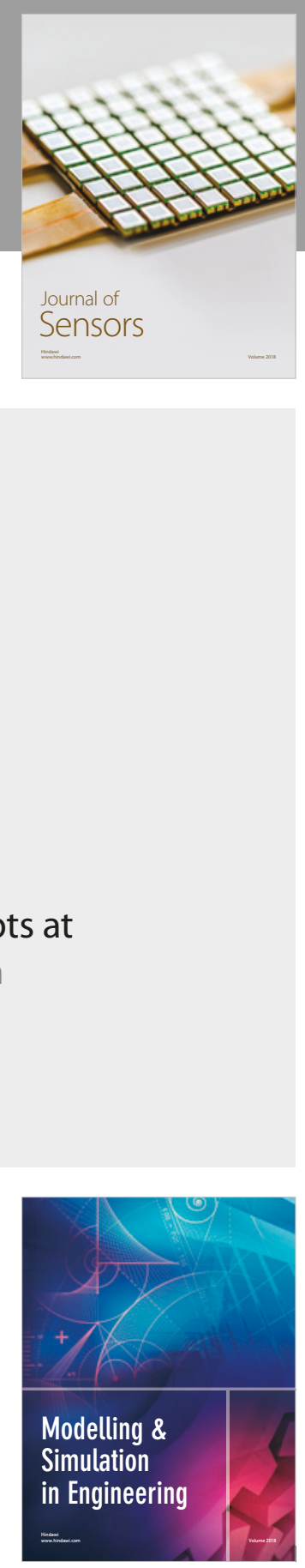

\section{Advances \\ Multimedia}
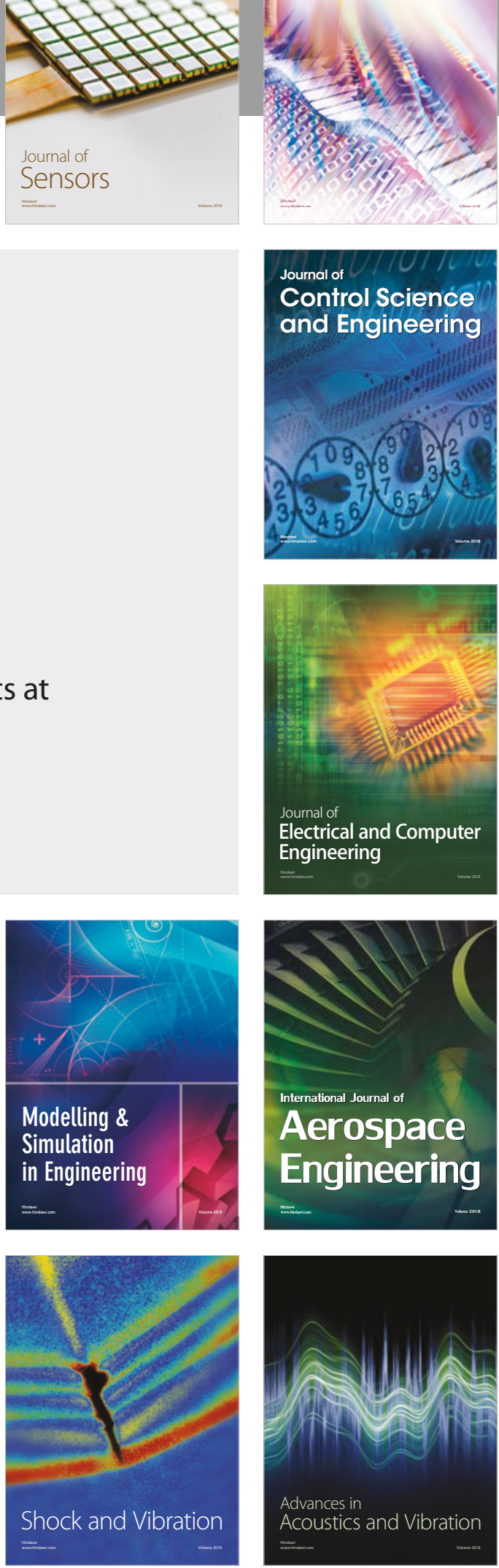